Eliane Cadoná ${ }^{1}$

Helena Scarparo ${ }^{1}$
${ }^{1}$ Programa de PósGraduação em Psicologia, Faculdade de Psicologia, Pontifícia Universidade Católica do Rio Grande do Sul. Av. Ipiranga 6681, Partenon. 90619-900 Porto Alegre RS Brasil. elianecadona@ yahoo.com.br

\title{
Construcionismo social na atenção básica: uma revisão integrativa
}

\author{
Social constructionism in primary health care: \\ an integrative review
}

\begin{abstract}
This study sets out to analyze scientific articles in order to investigate how researchers in the area of Social Constructionism define "health" in Primary Health Care. An integrative review of the literature was conducted along with a decision to concentrate on those works with narrative experiences and research studies. The database researched was the Brazilian Virtual Health Library, with experiences in the scope of Primary Health Care. The effectiveness of this step resulted in 12 articles. Data were analyzed and discussed based on the perspectives of social constructionism, which generated two central themes. They were: citizenship exercises - promoting health in collective spaces; health practices - overcoming the dichotomies and absolute truths. This study revealed the relevance of the notion of shared responsibility on meanings of health contained in the texts analyzed. The researchers claim that it is possible to expand health practices into collective action to facilitate ongoing dialogue between health users and workers. However, the dominance of biomedical discourse is criticized by the researchers, because that paradigm still promotes practices of care focused on illness.
\end{abstract}

Key words Health, Primary care, Social constructionism
Resumo O presente estudo propõe a análise de artigos científicos, com fins de investigar como autores/as que se apoiam no Construcionismo Social definem saúde na Atenção Básica. Foi realizada uma Revisão Integrativa, elegendo-se como materiais para discussão relatos de experiência e pesquisas publicadas na Biblioteca Virtual em Saúde Brasil, com exercícios no âmbito da Atenção Básica. A efetivação desta etapa resultou na coleta de 12 artigos. Os dados foram analisados e discutidos tendo como base as perspectivas do Construcionismo Social, o que gerou dois eixos temáticos: exercícios de cidadania - promoção de saúde nos espaços coletivos; práticas em saúde - $e$ a superação de dicotomias e verdades absolutas. Esse processo de estudo evidenciou a relevância da noção de responsabilidade compartilhada nos sentidos de saúde produzidos nos textos analisados. Os/as autores/as afirmam que é possivel ampliar as práticas em saúde para uma ação coletiva, que possibilite o contínuo diálogo entre usuários/ as e trabalhadores/as da saúde. Destaca-se ainda a crítica à predominância do discurso biomédico promotor de práticas coladas a lógicas de atenção centralizadas na doença.

Palavras-chave Saúde, Atenção básica, Construcionismo social 


\section{Introdução}

O presente estudo propõe a análise de artigos científicos, com fins de investigar como autores/ as que se apoiam no Construcionismo Social definem saúde na Atenção Básica. Objetivamos, assim, compreender de que modo práticas de saúde inspiradas nesse movimento intelectual traduzem seus pressupostos.

O Construcionismo carrega ideais ligados à movimentação do pensamento, aos deslocamentos e processos de mudança, lógica esta adotada por autores/as como Kenneth Gergen, Tomás Ibáñez, Lupicinio Iñiguez e Mary Jane Spink ${ }^{1}$. Em termos epistemológicos, insere-se na lógica do pensamento pós-moderno, com críticas a conceitos científicos instaurados na Modernidade. Esta última é marcada por um modo de fazer ciência pautado na racionalidade, objetividade, neutralidade, constância, continuidade e viabilidade, bem como pela noção de que o conhecimento é a representação da realidade e que existem verdades universais ${ }^{2}$.

Ao reconhecer que tais ideias ainda permanecem no modo contemporâneo de pensar e de fazer ciência, o pensamento construcionista denota uma postura crítica diante do mundo, no sentido de explicitar e debater os regimes de verdade presentes em noções como as de progresso, emancipação e liberdade. Com uma proposta que procura olhar para as relações e para os contextos em sua particularidade, esta linha de pensamento compreende que o conhecimento não é a representação da realidade e que as verdades são constituídas em territórios e tempos específicos.

Pensar sob essa perspectiva significa compreender que a construção da realidade se dá em meio aos coletivos e, portanto, não é possível falar de individualidades descoladas da cultura e dos modos que as pessoas elegem para vivenciar uma dada realidade. O Construcionismo Social analisa a produção de sentidos no cotidiano, fazendo da pesquisa uma possibilidade de misturar-se junto aos coletivos e compreender cada contexto em sua particularidade 3 . Compreender os processos pelos quais o humano descreve, explica e dá conta do mundo em um determinado período e espaço de tempo passa, então, a ser um dos principais objetivos desse modo de olhar para as relações, para as pessoas, para os acontecimentos ${ }^{4}$.

Tal movimento ganha destaque no campo da pesquisa nas últimas décadas do século $\mathrm{XX}^{1,5}$. No cenário da saúde brasileira, tem servido, ao longo dos últimos dez anos, como base para es- tudos relacionados ao cuidado humano, permitindo a discussão crítica de temas como violência conjugal, família, saúde mental, Atenção Básica, dentre tantos outros. Em meio a tais estudos, pesquisadores/as que se inspiram neste movimento reconhecem a importância do Construcionismo como dispositivo para pensar saúde $e^{4,6-9}$.

A Atenção Básica é definida pelo Ministério da Saúde como um conjunto de ações de caráter individual e coletivo que deve preconizar a promoção e proteção da saúde, a prevenção de agravos, o diagnóstico, o tratamento, a reabilitação, a redução de danos e a manutenção da saúde, por intermédio de práticas pautadas na integralidade, na universalidade e na equidade. Com uma proposta de trabalho de caráter interdisciplinar, prima pelo estabelecimento e fortalecimento dos vínculos e possui impressa em seu cerne a lógica de uma política de cunho relacional, que respeita os processos e modos de compreender saúde, marcados por espaços e culturas ${ }^{6}$.

Dentro desse contexto, acreditamos que propor práticas integradas implica o abandono de antigos paradigmas que associam a saúde à ausência de doença. Pensar o/a usuário/a de forma integral exige desvincular o cuidado de práticas diagnósticas taxativas e coladas a modelos de atenção direcionados à doença. Ao potencializar outros modos de vivenciar a realidade, com fins de proporcionar possibilidades sem negar a doença como processo que faz parte da vida, a Atenção Básica, pautada nessa lógica, evidencia o caráter político e comunitário de suas práticas ${ }^{6}$.

Tendo em vista a característica problematizadora das questões acima expostas, compreendemos que, na articulação entre a perspectiva construcionista e a Atenção Básica, brotam possibilidades de um fazer saúde que acompanha o movimento do cotidiano e os desejos, perspectivas e anseios das pessoas. Atentar-se para a forma como o Construcionismo Social é articulado à Política de Atenção Básica, em especial no âmbito de relações capitalistas, individualizadas e egoístas, permite a movimentação do pensamento para um fazer saúde aliado aos princípios aos quais se propõe. Impulsiona ainda a ideia de que as práticas deste campo de atenção precisam ser colocadas em questão a todo o momento, em prol de exercícios criativos e emancipatórios.

\section{Método}

Para conhecer as especificidades das noções de saúde na Atenção Básica, presentes em produ- 
ções científicas pautadas pelo Construcionismo Social, propomos um estudo, com base em publicações disponíveis na Biblioteca Virtual em Saúde Brasil (BVS Brasil), que possui um grande acervo de produções de livre acesso à população brasileira.

Levando-se em conta o objetivo do estudo, optou-se pela realização de uma Revisão Integrativa, que consiste em uma modalidade de produção acadêmica que possibilita a integração das mais variadas pesquisas, por intermédio da revisão de métodos, teorias e estudos empíricos sobre um tema específico. Este tipo de estudo propõese ainda a analisar e gerar ideias a respeito de uma área específica em estudo, respeitando etapas pré -estabelecidas de organização da revisão, que vão desde a elaboração do problema de pesquisa, até a análise e discussão dos resultados ${ }^{7,8}$. $\mathrm{O}$ termo de busca utilizado para pesquisa na base de dados, no primeiro semestre do ano de 2012, foi "Construcionismo Social”. Foram encontradas 51 produções e, através da leitura dos resumos, estabeleceram-se comparações entre os objetivos do estudo e a proposta de cada artigo. Os critérios de inclusão utilizados permitiram a seleção de pesquisas de campo e relatos de experiência, disponíveis na íntegra e em língua portuguesa, que propunham discussões desenvolvidas no âmbito da Atenção Básica, considerada a "porta de entrada" dos serviços de saúde no Brasil'. Entretanto, não se estabeleceram critérios em relação ao ano de publicação, sendo que todos os artigos recuperados na base de dados foram incluídos no presente estudo, desde que se relacionassem com o objetivo da revisão aqui proposta.

Artigos de revisão e que abordavam práticas na Atenção Secundária e Terciária não foram incluídos no presente estudo. Isso porque seu objetivo principal fundamenta-se na problematização de práticas descentralizadas, orientadas pelos princípios da universalidade, da acessibilidade, do vínculo, da continuidade do cuidado, da integralidade da atenção, da responsabilização, da humanização, da participação social e da equidade. Embora presentes nos demais níveis de atenção, os mesmos norteiam, em especial, as práticas da Atenção Básica. Tais princípios, articulados aos pressupostos do Construcionismo Social ${ }^{4}$, resultam na produção de textos com práticas voltadas para o "aqui-agora", sem formulações prévias, tendo em vista seu caráter participativo, relacional e o respeito às características geográficas e culturais de cada contexto.

Justificamos ainda nossa escolha pela discussão de estudos relacionados à Atenção Básica entendendo, por meio de nossas leituras e experiências no campo da Saúde Coletiva, que tal movimento também auxilia na descentralização da lógica hospitalocêntrica de atenção em saúde, promovendo debates e dando visibilidade a práticas realizadas em espaços comunitários de promoção de saúde.

A opção pela análise de artigos em português está aliada ao objetivo de associar a produção textual pesquisada às práticas de saúde partilhadas no contexto brasileiro. Assim, interessa colocar em análise práticas desenvolvidas no campo da saúde, com base na perspectiva construcionista, direcionadas ao público brasileiro e comprometidas com mudanças no âmbito nacional.

Para o desenvolvimento do trabalho e seleção dos artigos para composição do corpus, foram escolhidos termos que deveriam constar no título, resumo e/ou palavras-chave: Comunidade, Grupos/Grupos Comunitários, Atenção Básica, Atenção Primária, Estratégia Saúde da Família, Unidade de Saúde da Família, Promoção de Saúde, Prevenção Primária, Centros de Saúde/ Unidades de Saúde/Unidades Básicas de Saúde. Destaca-se que essa escolha deveu-se à análise de documentos e referências bibliográficas usualmente referidas por gestores/as e pesquisadores/ as das políticas públicas de saúde no Brasil ${ }^{10,11}$.

A efetivação desta etapa, que consistiu na leitura cuidadosa dos 51 artigos, na íntegra, teve como resultado 12 artigos que corresponderam aos critérios de seleção acima expostos, apresentados no Quadro 1.

Montada a coletânea de textos, foi realizada uma leitura criteriosa de cada uma das produções e construída uma tabela, com fins de coletar, junto aos estudos, dados como ano de publicação, região em que foram produzidos, bem como área de formação dos/as autores/as. Tais dados foram organizados, tendo em vista sua frequência relativa. Os demais dados, que forneceram os eixos temáticos a serem discutidos foram organizados, tendo em vista a referência completa da publicação, o objetivo principal do estudo, seu marco teórico norteador, o percurso metodológico utilizado para a produção do estudo, o resumo da obra e citações significativas relacionadas aos objetivos desta revisão.

A análise dos dados inspirou-se nas propostas de Spink ${ }^{12}$, que aborda o estudo das práticas discursivas em materiais de domínio público. Esse processo de análise resultou nos seguintes eixos temáticos: exercícios de cidadania - promoção de saúde nos espaços coletivos; práticas em saúde a superação de dicotomias e verdades absolutas. 


\begin{tabular}{|c|c|c|c|}
\hline \multirow[t]{14}{*}{ 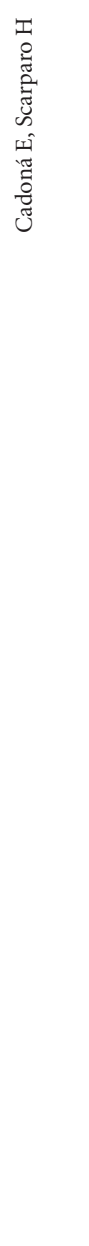 } & Quadro 1. Relação de artigos analisados. & & \\
\hline & Autores & Periódico & Ano de publicação \\
\hline & $\begin{array}{l}\text { Bulgarlli AF, Lorenzi CG, Carvalho da Silva R, } \\
\text { Mestriner SF, Villa TCS, Pinto IC. }\end{array}$ & Ciência \& Saúde Coletiva & 2012 \\
\hline & Camargo-Borges C, Japur M. & Interface (Botucatu) & 2005 \\
\hline & Camargo-Borges C, Mishima SM. & Saúde Soc. & 2009 \\
\hline & Eckerdt NS, Corradi-Webster CM. & Rev. Latino-Am. Enfermagem & 2010 \\
\hline & $\begin{array}{l}\text { Lenz-de-Oliveira K, Mendes dos Santos M, } \\
\text { Albuquerque de Moura S, Garcia WI, Gomes R. }\end{array}$ & Psicologia Ciência e Profissão & 2010 \\
\hline & Moreira RLCA, Rasera E. & Psicologia \& Sociedade & 2010 \\
\hline & Pedrosa CM. & Paidéia & 2009 \\
\hline & Pereira da Silva NHL, Cardoso CL. & Psicologia \& Sociedade & 2008 \\
\hline & Rasera E, Rocha RMG. & Psicologia em Estudo & 2010 \\
\hline & Ruwer de Azambuja MP, Nogueira C. & Ciência \& Saúde Coletiva & 2009 \\
\hline & Sampaio J, Paixão LA, Andrade PM, Torres TS. & Psicologia: Teoria e Prática & 2010 \\
\hline & Trench B, Rosa TEC. & Rev. Bras. Saúde Matern. Infant. & 2008 \\
\hline
\end{tabular}

\section{Análise e discussão dos resultados}

Em relação às produções analisadas, o ano destaque de publicações é o de 2010 (42\%), seguido do ano de 2009 (25\%), enquanto 2008 comporta $17 \%$ das produções, e 2005 e 2012, 8\%. O estado de São Paulo se sobressai em termos de número de estudos (53\%), o que pode ser atribuído ao fato do mesmo concentrar um maior número de escolas e centros de pesquisa, em comparação aos demais estados brasileiros.

Tais dados corroboram com os resultados de uma pesquisa sobre o número de publicações científicas efetuadas na América Latina, que acusa São Paulo, entre os anos de 2008 e 2010, como o estado responsável por $46 \%$ da produção nacional, quantidade que supera a produção de todos os países latino-americanos neste mesmo período $^{13}$. O segundo estado com maior representatividade de estudos é o de Minas Gerais (15\%), seguido dos estados do Amazonas, Bahia, Pernambuco e Santa Catarina (8\%).
Quanto à formação acadêmica, a maioria dos/as autores/as dos estudos em análise possui graduação em Psicologia (77\%). Um deles, na época da produção do artigo, estava em processo de formação (3\%). Em relação aos demais autores/as, $10 \%$ eram graduados/as em enfermagem, $7 \%$ em odontologia e 3\% em Pedagogia. Vale ressaltar que, em todos os artigos, ao menos um/a psicólogo/a possuía autoria.

Estes dados tornam-se relevantes para a discussão, em especial porque os estudos denunciam que a adoção do Construcionismo Social favorece os processos de inserção destes/as profissionais no campo da saúde, direcionado a um fazer comprometido e articulado às formas compartilhadas de compreensão e produção de sentidos da realidade. Este fato corrobora com a lógica da Atenção Básica, que dá preferência para as práticas locais, respeitando-se a cultura e a história de cada comunidade. A possibilidade de interlocução entre áreas evidencia, ainda que de forma tímida, em meio às produções, o desejo 


\section{Exercícios de cidadania}

- promoção de saúde nos espaços coletivos

As produções científicas aqui analisadas anunciam a articulação entre saúde e cidadania. Alinhadas aos princípios que norteiam a Atenção Básica, podemos dizer que o conceito de saúde que direciona tais ações afirma a responsabilidade de todos/as os/as atores/as no desenvolvimento de práticas em saúde, pautadas na autonomia, na corresponsabilidade, na integralidade e na formulação de vínculos, respeitando-se os saberes locais e os sentidos de saúde que circulam em meio aos contextos comunitários. A saúde, entendida como um fenômeno complexo pelos/ as autores/as, deixa de ser um ideal pautado em noções universais, dando-se ênfase à compreensão dos fatores que influenciam ou não o seu desenvolvimento ${ }^{14}$.

Ao realizar práticas de cuidado com base no conceito de saúde aqui adotado, os/as autores/as retratam um modelo de atenção que olha para o contexto e, por conta disso, compromete-se com a realidade que ali está posta. As práticas apresentadas nestes estudos ainda demonstram que o fazer em saúde está em constante processo de mudança, e que é possível promover espaços saudáveis em um trabalho em equipe, em que a proximidade com a realidade local permita enxergar e repensar, tanto junto aos/às trabalhadores/as quanto aos/às usuários/as, a forma como damos sentido à saúde ${ }^{15}$.

Tal postura demonstra o compromisso dos/as autores/as com a adoção de um posicionamento ético/político, cujo foco vai além da doença e do diagnóstico, possibilitando o exercício de cidadania por intermédio do protagonismo. A noção de coconstrução de autonomia ganha destaque neste contexto, à medida que se estimula, junto aos coletivos, a capacidade de reflexão de trabalhadores/as e usuários/as, promovendo práticas de liberdade comprometidas com o outro, tendo em vista que o exercício da autonomia se dá na relação ${ }^{16}$.

As ideias presentes nos artigos impelem assim a discussão política, e colocam em análise noções de "neutralidade", "objetividade" e "cientificidade", que, aliadas a uma negação da interferência inevitável da fronteira política nas práticas profissionais, constituí a noção posta na modernidade da ciência. A superação da cisão entre política e ciência pede, por sua vez, um olhar às práticas profissionais junto aos coletivos "no e com o mundo"17,18, em especial quando estas carregam um discurso pautado no compartilhamento de saberes e ações em prol da saúde das pessoas.

Desse modo, praticar saúde, conforme tais estudos, é "misturar-se" aos coletivos, é propiciar a formação de espaços dialógicos onde usuários/as e profissionais são ativos/as no exercício do fazer saúde. Sendo, neste contexto, a saúde entendida como um processo de criação, os/as autores/as dos textos compreendem que conceitos e práticas não devem ser definidos a priori, e que população e profissionais precisam engajar-se na construção de ferramentas de atenção que retratem conhecimentos e sentidos de ambos acerca da realidade em questão ${ }^{19}$.

Evidencia-se junto aos estudos que a ideia central dos autores/as é de que o conhecimento não está centralizado no/a profissional, devendo haver uma aproximação entre técnicos/as e população, atitude esta que servirá como base para ações em saúde comprometidas com uma dada realidade. Mais do que um/a simples receptor/a de receitas e modos de viver sua vida, o/a usuário/a é descrito/a nos textos como alguém que ocupa um lugar atuante em meio à equipe de saúde ${ }^{14,19}$. Convergentes à perspectiva construcionista, tais práticas reconhecem que o conhecimento não pode ser definido como resultado da indução e/ou formulação de hipóteses gerais, porque é transitório e marcado pelo território e, consequentemente, por sua história e cultura ${ }^{20}$.

Assim, as pesquisas e relatos de experiência presentes nos materiais analisados primam pelo desenvolvimento de estudos e práticas de saúde atrelados às necessidades do contexto que, ao ser considerado, circunscreve possibilidades de compreensão e descrição dos acontecimentos. A própria pesquisa é compreendida como forma engajada de ação sobre o mundo, capaz de movimentar sentidos, à medida que proporciona $\mathrm{o}$ diálogo desprovido de estereótipos e noções pretensiosas e pré-estabelecidas de ciência ${ }^{21}$.

Ao reconhecerem que ainda carregamos marcas do pensamento moderno, pesquisadores/ as que se apoiam na perspectiva construcionista entendem que as ciências humanas lidam com circunstâncias, fatos e acontecimentos que não se repetem, que não possuem uma continuidade e uma estabilidade. Por intermédio dessa lógica, concluem que não é possível estabelecer prin- 
cípios que fundamentem a interação humana, tampouco acumular conhecimento a respeito dessa questão porque todo conceito, norma, regra e verdade possui limitações históricas ${ }^{2,5}$.

O grupo, por sua vez, é visto nos materiais analisados como importante ferramenta de produção de espaços de democracia em saúde, desde que formalizado com fins de exercitar trocas e não com o objetivo de cristalizar ações e desenvolver práticas coladas única e exclusivamente à doença. A compreensão de que, ao mesmo tempo em que os/as profissionais adotam posturas tecnicistas e/ou moralistas, também são subjetivados pela cultura que, por sua vez, delineia um conceito de saúde por ele/a adotado, permite um olhar ampliado, tanto para com os/as usuários/ as, como para os/as trabalhadores/as, com fins de instigar outros modos de compreender a realidade, representada por discursos muitas vezes contraditórios e ambivalentes. Entretanto, chama-nos atenção, em meio aos textos, a noção de realização de grupos como sinônimo de garantia de promoção da participaçãao ${ }^{19,22,23}$.

Ao retomarmos os pressupostos da Política Nacional de Atenção Básica ${ }^{22}$, passamos a almejar um exercício comprometido com a política, com a promoção de cidadania e atento à realidade de cada usuário/a. Por outro lado, tais noções não apontam a técnica grupal como um imperativo. Pelo contrário: estimulam a utilização de técnicas e espaços variados atentos às necessidades demandadas. Ao intervir sob essa perspectiva, abrese a possibilidade de uso de diferentes formas de compartilhar sentidos, que se concretizam em meio às mais variadas técnicas lançadas por profissionais no campo da saúde.

Embora a perspectiva construcionista apareça como norteadora das práticas analisadas, percebe-se, ainda, em meio aos estudos, outros exemplos de ambiguidade paradigmática presentes em algumas ações relatadas. Como exemplo, tomamos a elaboração e distribuição, em meio aos estudos, de cartilhas e guias de saúde. Com objetivo de promover exercícios de cidadania, com a participação comunitária na elaboração dos materiais, estes, por outro lado, podem representar a cristalização de estereótipos, por intermédio da ideia de "dar voz", através de meios hegemônicos e que, após um tempo, já não farão mais parte daquela realidade. Guias, caminhos e alternativas de ações podem ser muito úteis nas intervenções, embora, dependendo da forma como usados, podem representar a ainda presente hegemonia de um fazer científico moderno pautado em leis gerais ${ }^{23}$, onde se acredita que preceitos estabelecidos em uma mesma comunidade sirvam para todos/as.

Mais uma vez, argumentamos aqui que toda ação, ainda que pautada em uma perspectiva emancipadora, possui suas limitações. Ao propor um caminho que se faz ao caminhar, os/as autores/as, inspirados/as no Construcionismo Social, também assumem riscos de cristalizar o pensamento, muitas vezes colocando em xeque até mesmo aquilo que defendem. É preciso reconhecer que vivemos em um mundo de contradições, ambiguidades e inconstâncias ${ }^{24}$, e que o fazer saúde nos espaços cotidianos desprendido de receitas e formulações prévias não nos assegura práticas descoladas da estereotipia e da produção de novas verdades. Assim, as práticas originadas da perspectiva construcionista também necessitam ser continuamente problematizadas, com fins de lançar-se um olhar crítico sobre seus efeitos no campo de intervenção.

Além disso, reconhecer o construcionismo como forma de partilhamento de sentidos não significa colocá-lo como único meio e razão de execução de práticas participativas e voltadas à promoção da saúde. O primeiro passo para a adoção de tal perspectiva é reconhecer que o partilhamento de ações, experiências e sentidos, sejam eles saudáveis ou não, já existem no cotidiano, cabendo ao/à profissional reconhecer seu espaço nos contextos, espaço este desvinculado de um fazer científico pretensioso e que desconsidera os demais saberes no processo de intervenção ${ }^{25}$.

Se muitos desses estudos em análise reconhecem a pesquisa como forma de partilhamento de ideias e produção de sentidos, precisamos também perguntar que noção de partilhamento existe em meio a estes discursos, e quem está realmente incluído/a nele, haja vista que as publicações acadêmicas ainda são acessadas, em sua maioria, apenas por pesquisadores/as e/ou intelectuais, nem sempre vinculados/as diretamente ao fazer saúde.

\section{Práticas em saúde - a superação} de dicotomias e verdades absolutas

Nos materiais discutidos no presente estudo relata-se a presença, ainda marcante, de discursos veiculados por profissionais e usuários/as, em que a saúde é relacionada à ausência de doença. Tais fatos são evidenciados por intermédio de temáticas ainda presentes nas práticas em saúde, tais como medicalização da vida e valorização do saber técnico na relação com os/as usuários/as que, por sua vez, são muitas vezes receptores/as 
desse discurso, por intermédio de uma postura passiva. Ainda que a linguagem utilizada pelos/as interventores/as se proponha a um fazer diferenciado, muitas vezes amplamente condizente com as políticas públicas em vigência, sentidos atribuídos ao seu fazer evidenciam um caráter higiênico e individualizado de atenção. A saúde, neste caso, é "alcançada" mediante prescrição médica e sua respectiva adoção, bem como isolamento de comportamentos de risco e desautorização da comunidade para cuidar de sua própria saúde $e^{26,27}$.

Tais atitudes relacionam-se ao modo como a saúde é compreendida na modernidade. Focada no investimento biopolítico, passa a ser reconhecida como elemento de governo da vida. Deixa de ser uma experiência ético-estética e transforma-se em uma estratégia de governo, com instrumentos ligados à medicalização e à normatização da vida ${ }^{28,29}$.

Exemplos como esses foram relatados em meio à dificuldade de interventores/as em exercer uma prática de cuidado em educação sexual junto a adolescentes ${ }^{30}$. Em muitos casos, estes últimos são posicionados como incapazes de cuidar de sua própria vida sexual e, portanto, impossibilitados de manter relações até que algum/a profissional diga que isso é possível. O temor dos/as profissionais pela possibilidade de que tal população se contagie atrela-se aos dados de outros estudos, que evidenciaram a dificuldade de Agentes Comunitários de Saúde em trabalhar com portadores de HIV/AIDS sob uma perspectiva de promoção de saúde ${ }^{31}$.

Tal conceituação apoia-se em uma lógica dicotômica de atenção, e que, consequentemente, separa o bom do mau, o doente do são, a vítima do agressor, o incluído do excluído, a saúde da saúde mental. A realidade, muito diferente disso, convive com todas essas facetas e, ao procurar separá-las com um olhar de juízo de valor, o/a especialista impossibilita o diálogo e promove mais sofrimento ao impor condições e modos de ação que não condizem ou não suprem com a demanda apresentada.

Ao evidenciar as questões acima expostas, é válido ressaltar que o projeto da modernidade, que conduziu a ciência a enquadrar-se em seus moldes, confirmou o desejo em criarem-se modelos universais. A exemplo dessa lógica tomamos o atual, abrangente e inalcançável - porque marcado por ideais de um determinado tempo e espaço - conceito de saúde proposto pela Organização Mundial de Saúde, que a compreende como um completo bem-estar físico, mental e social, e não simplesmente como ausência de doença. Ao generalizar tal conceito, reforça-se o caráter dicotômico das práticas, à medida que mais uma vez se preconiza um ideal universal e, consequentemente, um padrão de vida e de bem -estar ${ }^{32}$.

Evidenciam-se, em meio a esse cenário da saúde na contemporaneidade, ações que ainda atrelam práticas a uma postura normativa e curativista. Sair dessa lógica implica promover rupturas de paradigmas, com um olhar voltado menos para a doença e mais para o sujeito. Direciona para a adoção de posturas pautadas no paradigma da promoção de saúde, na transformação social, em processos participativos onde prescrições de caráter individualizado dão espaço para a responsabilização de diversos setores e coletivos no exercício do cuidado ${ }^{33,34}$. Adotada essa atitude, as práticas em saúde e os conceitos formulados são considerados locais, transitórios e de caráter participativo, enxergando a realidade em seus diferentes prismas.

As questões de gênero, discutidas em um número considerável de artigos aqui analisados, por exemplo, são problematizadas colocando-se em questão o quanto a produção de dicotomias acaba posicionando os sujeitos em situações de vulnerabilidade em seu cotidiano ${ }^{26,35,36}$. Isso porque, ao reforçar as diferenças entre os sexos como condição para a produção de comportamentos de passividade e agressividade, homens e mulheres assumem papéis que não lhes permitem vivenciar a sexualidade ligada ao cuidado de si e do outro.

Tais atitudes acima evidenciadas são reforçadas por outra postura apontada pelos/as autores/ as dos artigos e especialistas de saúde: a do expert, cujos saberes a sociedade não se atreve a questionar. Assim, o/a profissional torna-se o/a detentor/a de um conhecimento que a comunidade não tem, ditando o caminho a ser seguido por ela para chegar a um "ideal" de comportamento "saudável”. O modelo de atenção em saúde de caráter curativista, positivista, medicalizado e vertical reduz a intervenção focando-a na doença, o que reforça, muitas vezes, estereótipos e preconceitos comunitários ${ }^{26,36}$.

Podemos relacionar esse movimento às problematizações sobre a Modernidade Tardia, termo atrelado ao momento atual o qual a humanidade experiencia. Para Spink ${ }^{37}$, não podemos afirmar que superamos características e modos de vivenciar a realidade presentes na modernidade. Pelo contrário, embora devamos reconhecer que estamos vivendo um momento diferente daquele em que ocorreu a passagem do Feudalismo 
para a Modernidade, possuímos características marcantes de todos esses tempos históricos que garantiram a permanência de determinadas crenças e costumes, a exemplo do modelo de atenção em saúde pautado em pressupostos biologicistas e atentos ao controle e erradicação do "anormal".

Esta mesma ação ainda adotada no campo da saúde - e que muitas vezes convive lado a lado com práticas de cuidado que condizem com os princípios da Atenção Básica -, desautorizam a comunidade a cuidar de sua própria saúde, sendo os/as profissionais autorizados a dizer como, em que momento e de que forma determinadas práticas devem ser exercitadas. Ao deparar-se com as mesmas prescrições, porque pautadas em uma ideia universal e essencializada de humano, pessoas diferentes, que vivem em contextos distintos, passam a enxergar um abismo entre a prática prescrita e a forma como vivenciam a realidade. Tudo isso faz com que se afastem cada vez mais dos serviços de saúde e, diante deles, mantenham a postura que lhes é conferida: a de passividade.

Em meio a toda essa discussão, reconhece-se a manutenção da prática em saúde no cotidiano ligada ao paradigma biomédico de atenção, com centralização na cura, no tratamento e na prevenção ${ }^{29}$. Quando visualizamos, sob essa perspectiva, a submissão das comunidades ao saber dos/as profissionais, intelectuais, experts, é preciso, ao mesmo tempo, compreender que tal realidade só se mantém porque as pessoas sustentam essa lógica. Se, por um lado, usuários/as são convidadas a ocupar o espaço de submissão a um determinado saber, os/as profissionais igualmente entram nessa engrenagem discursiva, submetendo-se, do mesmo modo, a um modelo hegemônico por intermédio do qual também são subjetivados/as. Em outras palavras, não há mocinhos/as e bandidos/as, mas sim posições alimentadas junto aos coletivos que sustentam determinadas relações de poder-saber e a permanência de determinados regimes de verdade ${ }^{38}$, dos quais talvez não estejamos dispostos/as a nos desfazer.

Destacamos assim que os artigos evidenciam uma postura passiva da população até mesmo diante de práticas ditas emancipatórias e participativas, e a consequente espera da mesma por modelos e prescrições. Cabe-nos problematizar de que forma o discurso da participação, presente em documentos oficiais como a Constituição Federal $^{39}$ e a Lei número 8.142, publicada no Brasil em 1990, chegou até os espaços coletivos.

Embora a proposta da Reforma Sanitária tenha nascido em meio aos movimentos populares, com envolvimento de trabalhadores/as, militan- tes e da população em geral $^{40}$, desconhecemos o acesso ou até mesmo os sentidos partilhados pelas comunidades sobre participação. Em um contexto em que o saber biomédico é reconhecido como principal sinônimo de exercício de saúde, fica evidente a dificuldade de implantação de um modelo participativo que mede forças com uma lógica de atenção que não comunga com tais princípios.

\section{Algumas considerações}

O movimento construcionista presente nas ideias explanadas nas produções evidencia a compreensão do conceito de saúde como uma produção humana, carregada de sentidos atrelados a questões de gênero, raça, etnia, classe social e gerações, bem como a saberes técnico/científicos adotados no cotidiano. A lógica do acúmulo de um conhecimento dito universal e permanente dá espaço para o exercício cotidiano de construção de ações inovadoras, locais e condizentes com as necessidades do contexto, em especial, pela noção adotada de que não há conhecimento que ultrapasse sua limitação histórica ${ }^{5}$.

O Contrucionismo Social também é adotado em meio às produções como ferramenta teórico/metodológica. Ao defender a ideia de que, ao problematizar sentidos, é possível mudar uma dada realidade, este movimento, articulado à lógica da Atenção Básica, é utilizado nos estudos analisados como possibilidade de usuários/as e trabalhadores/as construírem materiais e ações que potencializem a troca de experiências e a mudança da realidade que gera sofrimento. Com fins de não reduzir fenômenos do cotidiano a explicações universais e direcionadas à culpabilização, essa perspectiva reconhece o caráter processual e contraditório da realidade $e^{35,41}$.

Em meio a estes estudos, foi possível ainda evidenciar que o paradigma que norteou as ações em saúde primava por uma postura que não se fixava no tecnicismo, mas na ideia de, ao chegar à comunidade, o/a profissional precisa, antes de qualquer coisa, inserir-se, por intermédio da escuta e de caminhos que possibilitem abertura aos estranhamentos. Esse primeiro passo de aproximação aos sentidos que a comunidade atrela à saúde e à doença permitiram, em meio a essas práticas, propostas de intervenção criativas, que extrapolam os muros dos consultórios e não veem na medicalização e na individualização dos problemas a solução para promover saúde ${ }^{19}$.

Propondo mudanças no campo da saúde, os 
estudos analisados demonstram a necessidade de modificação de posicionamento no exercício de determinadas ações, tendo em vista que as práticas tradicionais não apresentam benefícios para o exercício da saúde nos espaços coletivos e não condizem com as atuais lógicas de atenção adotadas pelas políticas públicas nacionais.

Foi possível enxergar, em meio às produções, que o Construcionismo Social se constitui como importante impulsionador de ações em saúde, em especial porque comunga com os princípios norteadores da Atenção Básica e porque é utilizado, a exemplo dos artigos em análise neste estudo, para exercitar espaços de reflexão que permitem inclusive a reavaliação da postura do/a interventor/a.

Instiga-nos, neste contexto, a presença, ainda marcante, do modelo de atenção pautado no risco e na doença, o que gera o exercício de práticas de caráter preventivista e prescritor. Cabe-nos questionar que espaços a perspectiva construcionista pode conquistar em meio a essa lógica,

\section{Colaboradores}

As autoras tiveram igual participação em todas as etapas de elaboração do artigo. e de que forma a análise das práticas discursivas permite evidenciar ações que mantêm a saúde dentro do paradigma da doença e que são partilhadas e reconhecidas como modelo principal de atenção pela população em geral.

Por fim, cabe ainda apontar que, embora a pesquisa construcionista carregue um viés emancipador de práticas de liberdade, associada ao fazer junto às comunidades, faz-se necessário reconhecer que as produções que foram mote de discussão na presente revisão são acessadas por poucos/as, muitas vezes por aqueles/as que, de uma forma ou de outra, insistem em sustentar o paradigma biomédico por eles/as criticado. E, com isso, finalizamos, perguntando: a pesquisa construcionista atinge os coletivos? E se atinge, de que forma o faz? Tais perguntas nos convidam a pensar que, além da produção de pesquisas bem elaboradas e articuladas à legislação nacional, precisamos investigar de que forma elas são compartilhadas nos espaços e nas práticas que desejamos movimentar.

\section{Referências}

1. Méllo RP, Avarez Silva A, Di Paolo AF. Construcionismo, práticas discursivas e possibilidades de pesquisa em psicologia social. Psicologia \& Sociedade 2007; 19(3):26-32.

2. Îñiguez L. Construcionismo Social. In: Martins JB, organizador. Temas em Análise Institucional e em Construcionismo Social. São Carlos: Rima; 2002. p. 97-180.

3. Gergen MM, Gergen KJ. Construcionismo social: um convite ao diálogo. Rio de Janeiro: Instituto Noos; 2010.

4. Gergen KJ. O movimento do construcionismo social na psicologia moderna. INTERthesis 1985/2009; 6(1):299-325.

5. Rasera EF, Japur M. Os sentidos da construção social: o convite construcionista para a psicologia. Paidéia 2005; 15(30):21-29.

6. Brasil. Ministério da Saúde (MS). Secretaria de Atenção à Saúde. Departamento de Atenção Básica. Política Nacional de Atenção Básica. Brasília: MS; 2012.

7. Mendes KDS, Silveira RCCP, Galvão CM. Revisão integrativa: método de pesquisa para a incorporação de evidências na saúde e na enfermagem. Texto Contexto Enferm 2008; 17(4):758-764.

8. Botelho LLR, Cunha CCA, Macedo M. O método da revisão integrativa nos estudos organizacionais. Gestão e Sociedade 2011; 5(11):121-136.

9. Brasil. Conselho Nacional de Secretários de Saúde. Atenção Primária e Promoção da Saúde. Brasília: CONASS; 2007. 
10. Andrade LOM, Bueno ICHC, Bezerra RC. Atenção Primária à Saúde e Estratégia Saúde da Família. In: Campos GWS, Minayo MCS, Bonfim JRA, Akerman M, Drumond júnior M, Carvalho YM, organizadores. Tratado de Saúde Coletiva. São Paulo: Hucitec; 2012. p. 783-836.

11. Brasil. Lei no 8.080 de 19 de setembro de 1990. Dispõe sobre as condições para a promoção, proteção e recuperação da saúde, a organização e o funcionamento dos serviços correspondentes e dá outras providências. Diário Oficial da União 1990; 19 set.

12. Spink P. Análise de documentos de domínio público. In: Spink MJ, organizadora. Práticas discursivas e produção de sentidos no cotidiano. São Paulo: Cortez; 2000 p. 123-151.

13. Fundação de Amparo à Pesquisa do Estado de São Paulo (FAPESP). Indicadores Fapesp de Ciência, Tecnologia e Inovação. Pesquisadores no Brasil publicam 56\% dos artigos científicos originados na América Latina. São Paulo: FAPESP; 2011. boletim número 23.

14. Bulgarelli AF, Lorenzi CG, Carvalho da Silva R, Mestriner SF, Villa TCS, Pinto IC. Atenção primária à saúde e a construção de sentidos para a saúde bucal: leitura construcionista social sobre discursos de idosos. Cien Saude Colet 2012; 17(8):2053-2062.

15. Camargo-Borges C, Japur M. Promover e recuperar saúde: sentidos produzidos em grupos comunitários no contexto do Programa de Saúde da Família. Interface (Botucatu) 2005; 9(18):507-519.

16. Campos RTO, Campos GWS. Co-construção de autonomia: o sujeito em questão. In: Campos GWS, Minayo MCS, Bonfim JRA, Akerman M, Drumond Júnior M, Carvalho YM, organizadores. Tratado de Saúde Coletiva. São Paulo: Hucitec; 2012. p. 669-688.

17. Coimbra CMB. Psicologia e política: a produção de verdades competentes. 2002 [acessado 2013 jul 1] [12 p.]. Disponível em: http://www.crprj.org.br/documentos/2011-psicologia_politica.pdf.

18. Prado MA. Fronteiras Negadas: contribuições da psicologia política para a compreensão das ações políticas In: Mayorga C, Prado MAM, organizadores. Psicologia Social: articulando saberes e fazeres. Belo Horizonte, São Paulo: Autêntica; 2008. p. 99-112.

19. Camargo-Borges C, Mishima SM. Responsabilidade relacional como ferramenta útil para a participação comunitária na Atenção Básica. Saúde Soc 2009; 18(1):2941.

20. Gergen K. Psicologia social como história. Psicologia \& Sociedade 2008; 20(3):475-484

21. Eckerdt NS, Corradi-Webster CM. Sentidos sobre o hábito de fumar para mulheres participantes de grupo de tabagistas. Rev. Latino-Am. Enfermagem 2010; 18(n. esp.):641-647.

22. Campos GWS. Clínica e saúde coletiva compartilhadas: teoria paidéia e reformulação ampliada do trabalho em saúde. In: Campos GWS, Minayo MCS, Bonfim JRA, Akerman M, Drumond Júnior M, Carvalho YM, organizadores. Tratado de Saúde Coletiva. São Paulo: Hucitec; 2012. p. 41-80

23. Foucault M. A Psicologia de 1850 a 1950. In: Foucault M. Ditos e escritos I. Rio de Janeiro: Forense Universitária; 2002. p. 122-139.

24. Baumam Z. Modernidade líquida. Rio de Janeiro: Zahar; 2001.
25. Baremblitt G. Compêndio de análise institucional e outras correntes: teoria e prática. Belo Horizonte: Instituto Félix Guattari; 2002.

26. Trench B, Rosa TEC. Menopausa, hormônios, envelhecimento: discursos de mulheres que vivem em um bairro na periferia da cidade de São Paulo, Estado de São Paulo, Brasil. Rev. Bras. Saúde Matern. Infant. 2008, 8(2):207-216.

27. Rasera E, Rocha RMG. Sentidos sobre a prática grupal no contexto de saúde pública. Psicologia em Estudo 2010; 15(1):35-44.

28. Foucault M. Em defesa da sociedade. Curso no Collège de France (1975-1976). São Paulo: Martins Fontes; 2005.

29. Bernardes AGB. Potências no campo da saúde: o cuidado como experiência ética, política e estética. Bárbaroi 2012; (36):175-190.

30. Sampaio J, Paixão LA, Andrade PM, Torres TS. Gênero, sexualidade e práticas de prevenção das DST/Aids: produções discursivas de profissionais da saúde da família e de adolescentes do Vale do São Francisco. Psicologia: Teoria e Prática 2010; 12(2):173-187.

31. Pereira da Silva NHL, Cardoso CL. Agentes Comunitárias de Saúde: sentidos acerca do trabalho em HIV/ AIDS. Psicologia \& Sociedade 2008; 20(2):247-256.

32. Contini MLJ. O psicólogo e a promoção de saúde na educação. São Paulo: Casa do Psicólogo; 2001

33. Ayres JRCM. Uma concepção hermenêutica de saúde. Physis 2007; 17(1):43-62.

34. Westphal MF. Promoção de saúde e prevenção de doenças. In: Campos GWS, Minayo MCS, Bonfim JRA, Akerman M, Drumond Júnior M, Carvalho YM, organizadores. Tratado de Saúde Coletiva. São Paulo: Hucitec; 2012. p. 635-667.

35. Pedrosa CM. A construção de uma ferramenta social para promoção da saúde e dos direitos das mulheres. Paidéia 2009; 19(42):123-129.

36. Moreira RLCA, Rasera E. Maternidades: os repertórios interpretativos utilizados para descrevê-las. Psicologia \& Sociedade 2010; 22(3):529-537.

37. Spink M. Linguagem e produção de sentidos no cotidiano. Rio de Janeiro: Centro Brasileiro de Pesquisas Sociais; 2012.

38. Eizirik MF. Poder, saber e práticas sociais. Psico 2006; 37(1):23-29.

39. Brasil. Constituição da República Federativa do Brasil de 1988. Diário Oficial da União 1988; 5 out

40. Scarparo H. Psicologia Comunitária no Rio Grande do Sul: Registros da Construção de um saber-agir. Porto Alegre: EDIPUCRS; 2005.

41. Lenz-de-Oliveira K, Mendes dos Santos M, Albuquerque de Moura S, Garcia WI, Gomes R. Elaborando uma cartilha sobre as ambigüidades da violência conjugal. Psicologia Ciência e Profissão 2010; 30(2):428-439.

Artigo apresentado em 12/05/2014

Aprovado em 22/09/2014

Versão final apresentada em 24/09/2014 